\title{
Radioisotope Power: A Key Technology for Deep Space Exploration
}

\author{
George R. Schmidt and Thomas J. Sutliff \\ NASA Glenn Research Center, Cleveland, Ohio, 44135 \\ Leonard A. Dudzinski \\ NASA Headquarters, Washington, D.C., 20546
}

A Radioisotope Power System (RPS) generates power by converting the heat released from the nuclear decay of radioactive isotopes, such as Plutonium-238 (Pu-238), into electricity. First used in space by the U.S. in 1961, these devices have enabled some of the most challenging and exciting space missions in history, including the Pioneer and Voyager probes to the outer solar system; the Apollo lunar surface experiments; the Viking landers; the Ulysses polar orbital mission about the Sun; the Galileo mission to Jupiter; the Cassini mission orbiting Saturn; and the recently launched New Horizons mission to Pluto. Radioisotopes have also served as a versatile heat source for moderating equipment thermal environments on these and many other missions, including the Mars exploration rovers, Spirit and Opportunity. The key advantage of RPS is its ability to operate continuously, independent of orientation and distance relative to the Sun. Radioisotope systems are long-lived, rugged, compact, highly reliable, and relatively insensitive to radiation and other environmental effects. As such, they are ideally suited for missions involving long-lived, autonomous operations in the extreme conditions of space and other planetary bodies. This paper reviews the history of RPS for the U.S. space program. It also describes current development of a new Stirling cycle-based generator that will greatly expand the application of nuclear-powered missions in the future. 

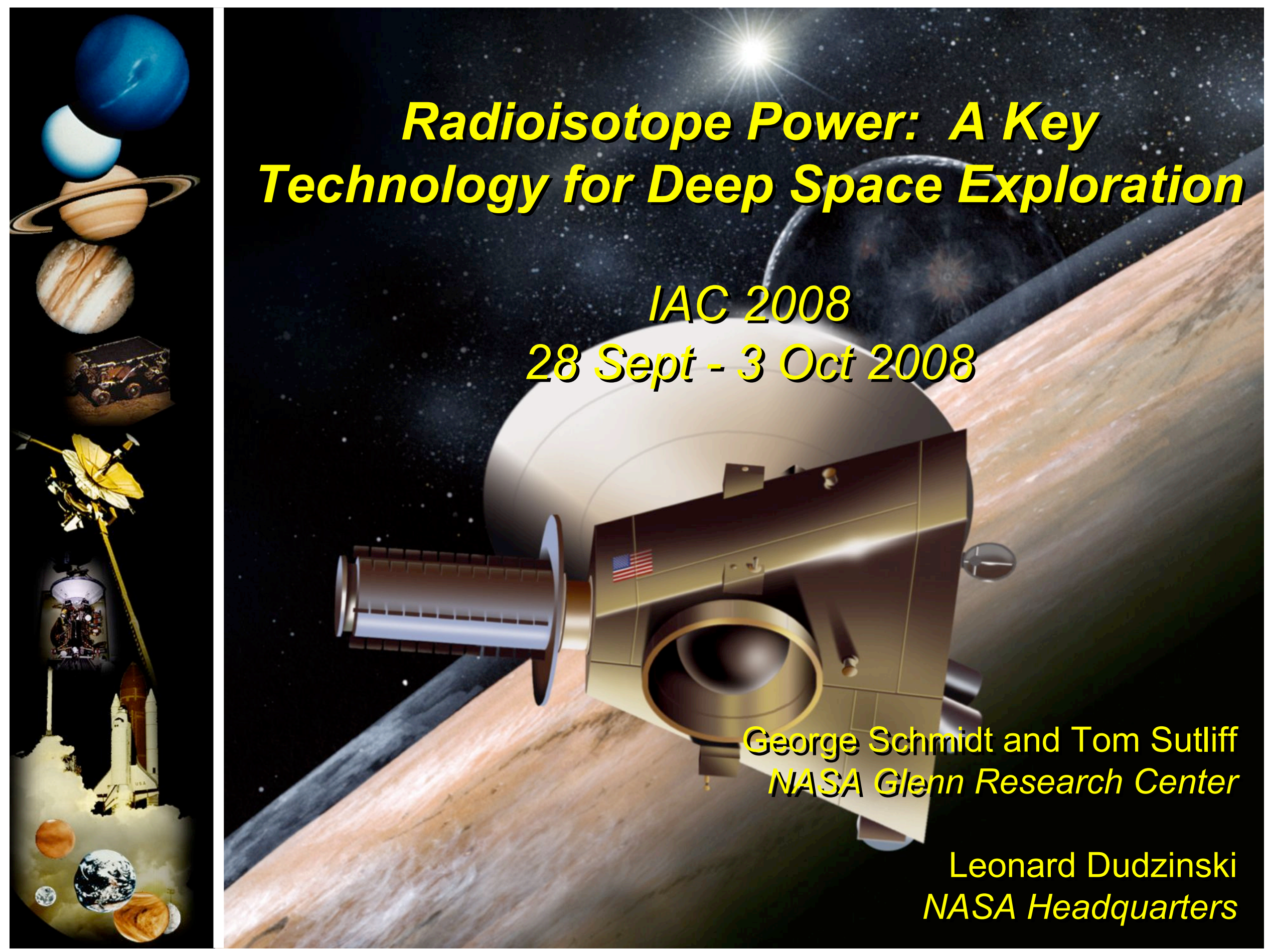


\section{Radioisotope Power Systems (RPS)}

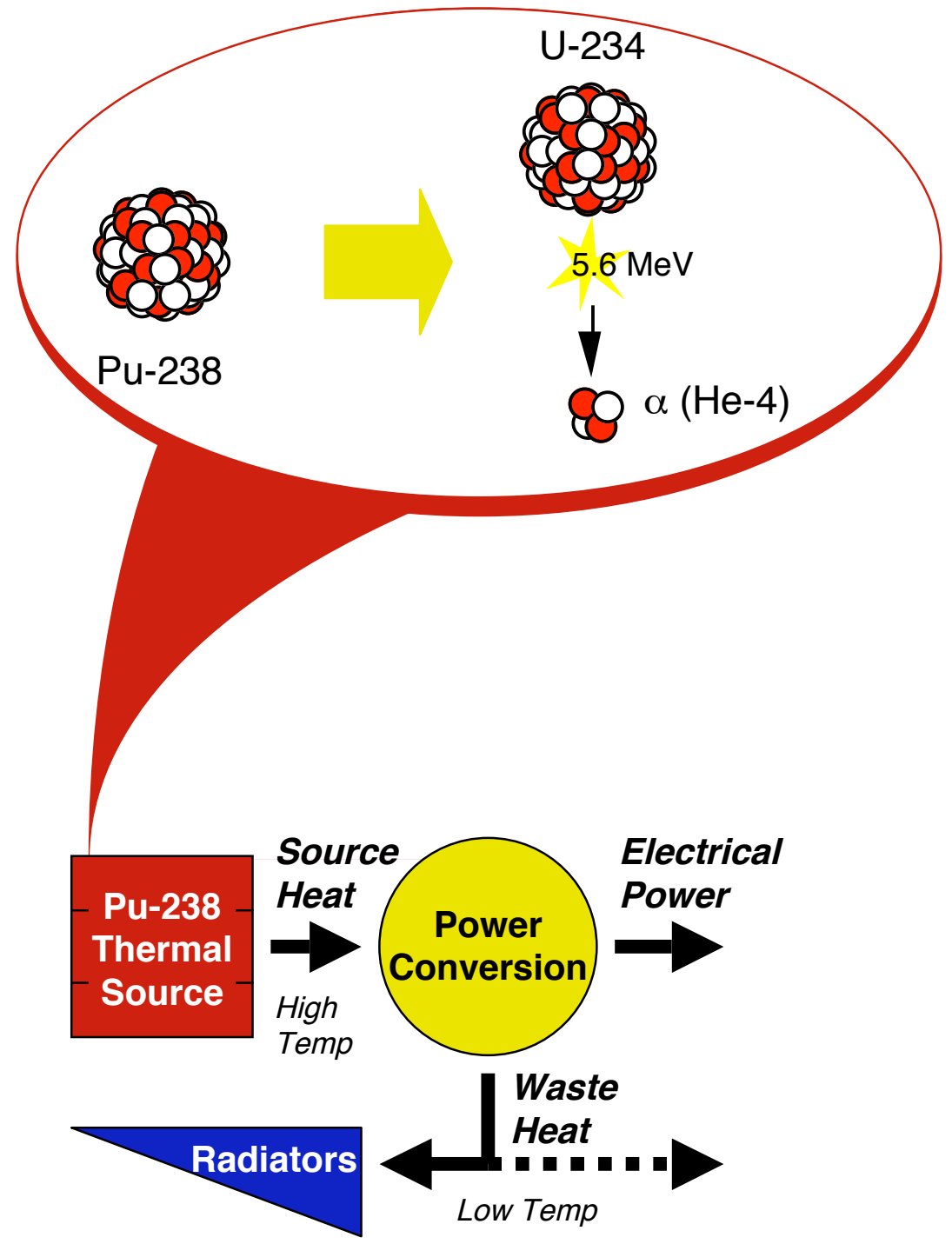

- Heat produced from natural alpha $(\alpha)$ particle decay of Plutonium (Pu-238)

- 87.7-year half-life

- Small portion of heat energy (6\%-35\%) converted to electricity via passive or dynamic processes

- Thermoelectric (existing \& under development)

- Stirling (under development)

- Brayton, TPV, etc. (future candidates)

- Waste heat rejected through radiators portion can be used for thermal control of spacecraft subsystems

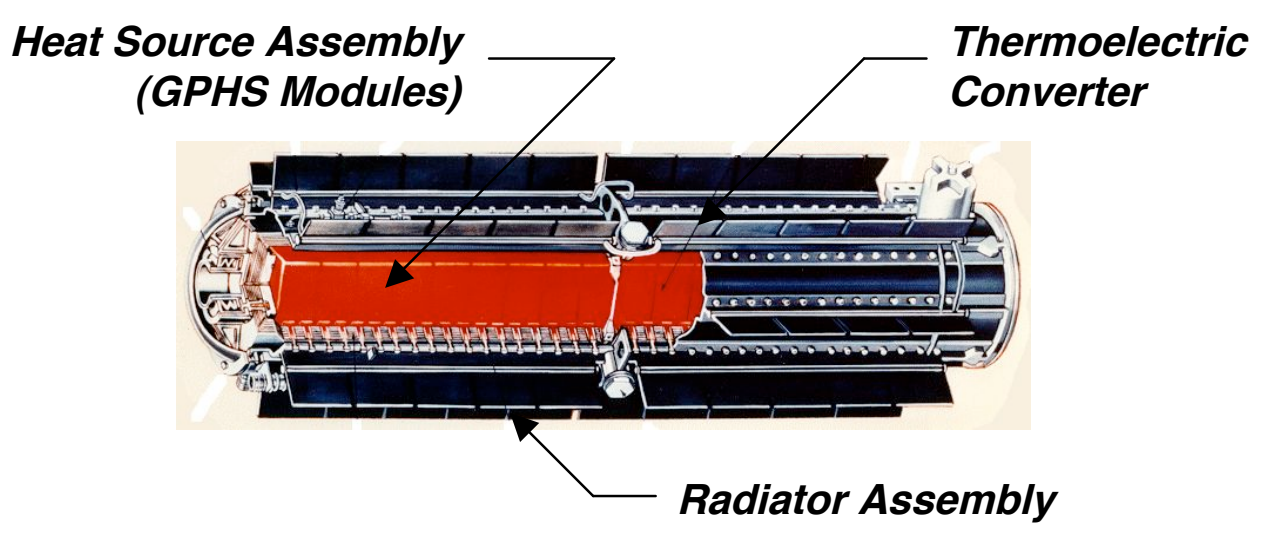

GPHS-Radioisotope Thermoelectric Generator (RTG) 


\section{Benefits of RPS}

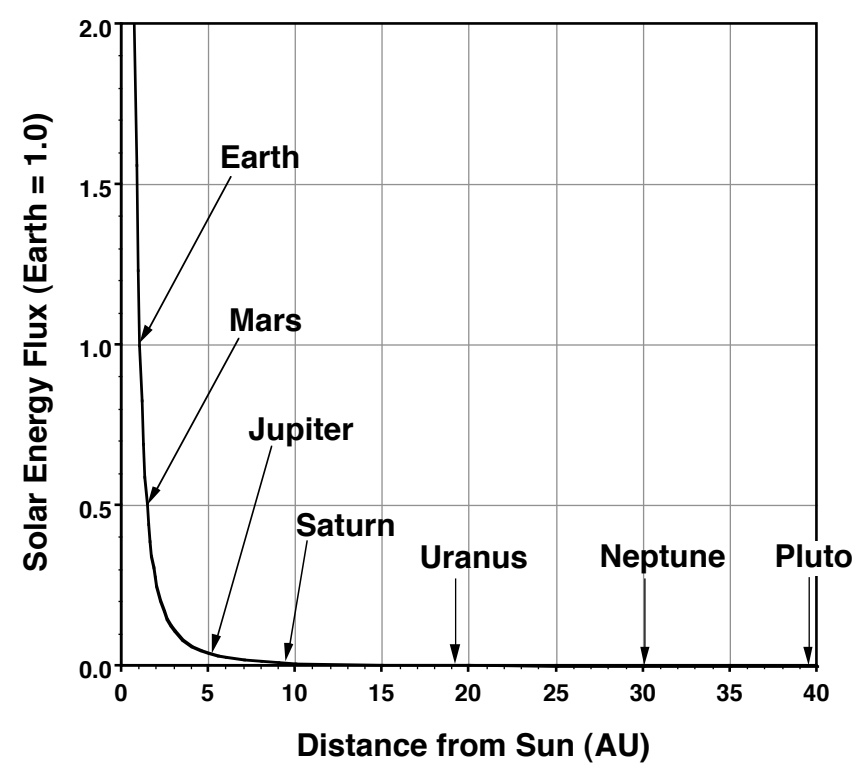

\section{Unique features of nuclear power}

- Steady power independent of distance and orientation w/respect to Sun;

- Operation in thick atmospheres and shadowed areas;

- Operation in extreme and high-radiation environments (e.g., Venus, Titan, Jovian space);

- Long duration operation ( $\geq 10$ years);

\section{Added advantages of:}

- Scalability to very low power levels $(\leq 1-10 \mathrm{kWe})$;

- Use in close proximity to crew (low penetrating radiation);

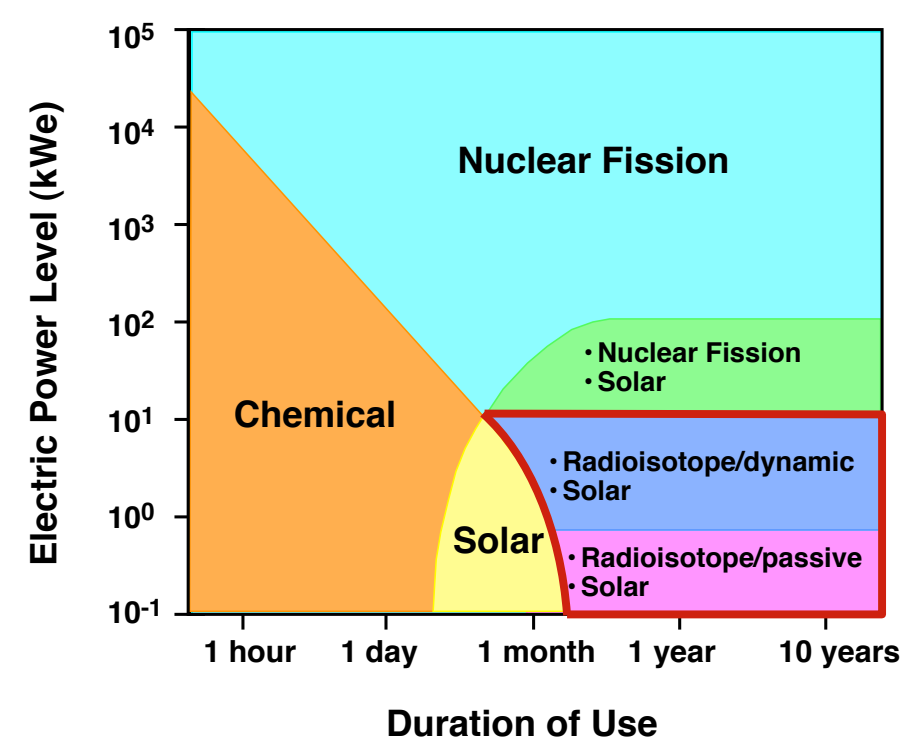

- Readily available excess heat;

- Compactness and ease of transport;

- Enables Radioisotope Electric Propulsion (REP) benefits of NEP with low power spacecraft (1-5 kWe)

- High-performance electric propulsion in deep space

- Specific powers comparable to near-term reactor-based NEP

- Much smaller spacecraft

Duration of Use 


\section{U.S. Radioisotope Space Missions}

41 RTGs used successfully on 23 spacecraft since 1961

- 8 Planetary (Pioneer, Voyager, Galileo, Ulysses, Cassini, New Horizons)

- 8 Earth Orbit (Transit, Nimbus, LES)

- 5 Lunar Surface (Apollo ALSEP)

- 2 Mars Surface (Viking)

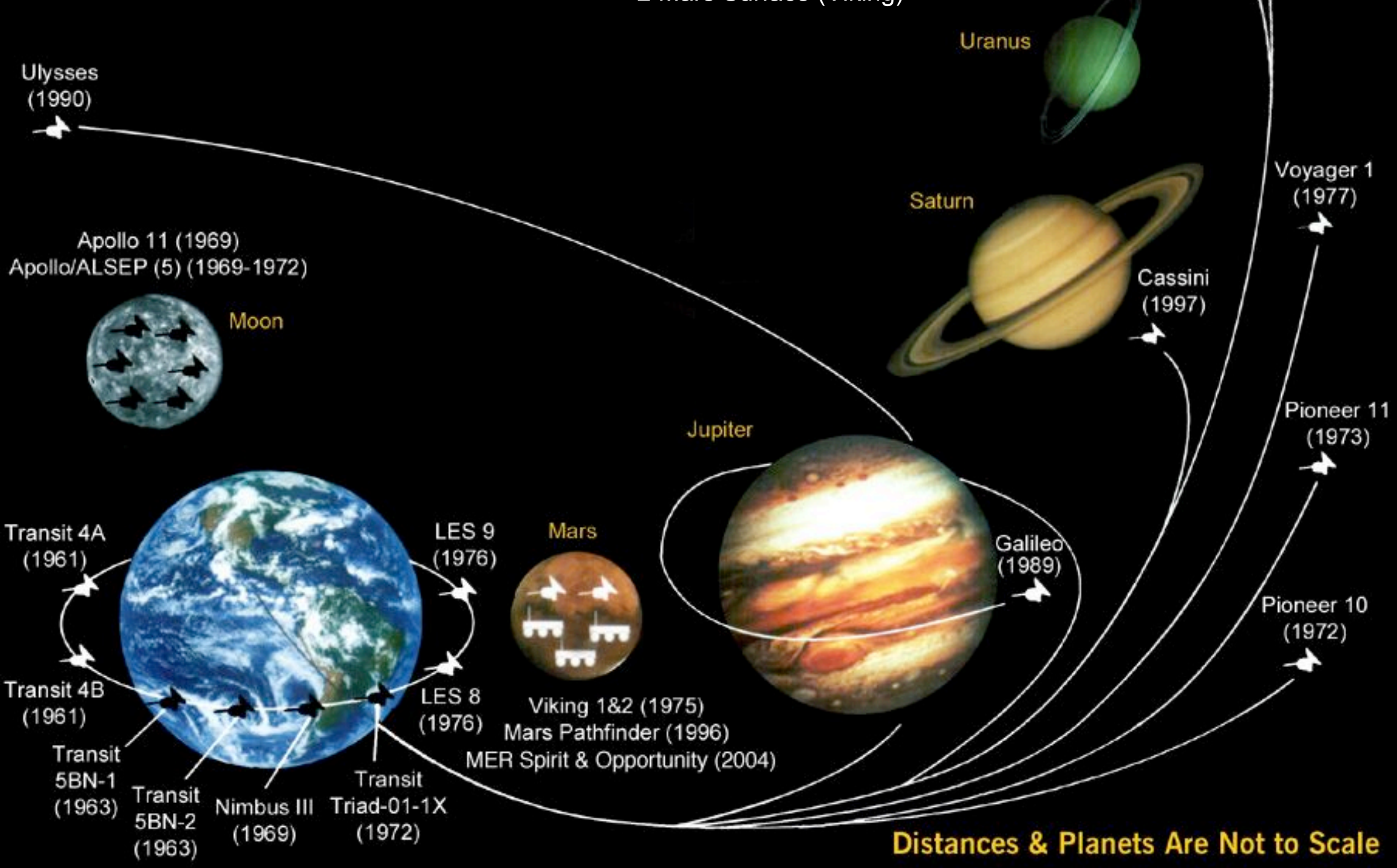




\section{Early Days}

- Original impetus was national security surveillance satellites. Potential for RPS identified by North American Aviation and RAND in late-1940's.

- In early-1950's, DOD requested AEC to conduct studies and technology work on space nuclear power. AEC broadened consideration to radioisotopes. Origin of Systems for Nuclear Auxilliary Power (SNAP).

- Early SNAP efforts focused on dynamic energy conversion. SNAP-1 was Ce-144 powered Mercury Rankine generator.

- Thermoelectric energy conversion invented at AEC's Mound Laboratory by Kenneth Jordan and John Birden in 1954.

- SNAP-3 project developed thermoelectric-based device using Polonium-210 fuel.

- President Eisenhower used SNAP-3 to advocate expanded use of space nuclear power, particularly for NASA. Becomes marketing centerpiece of "Atoms for Peace."

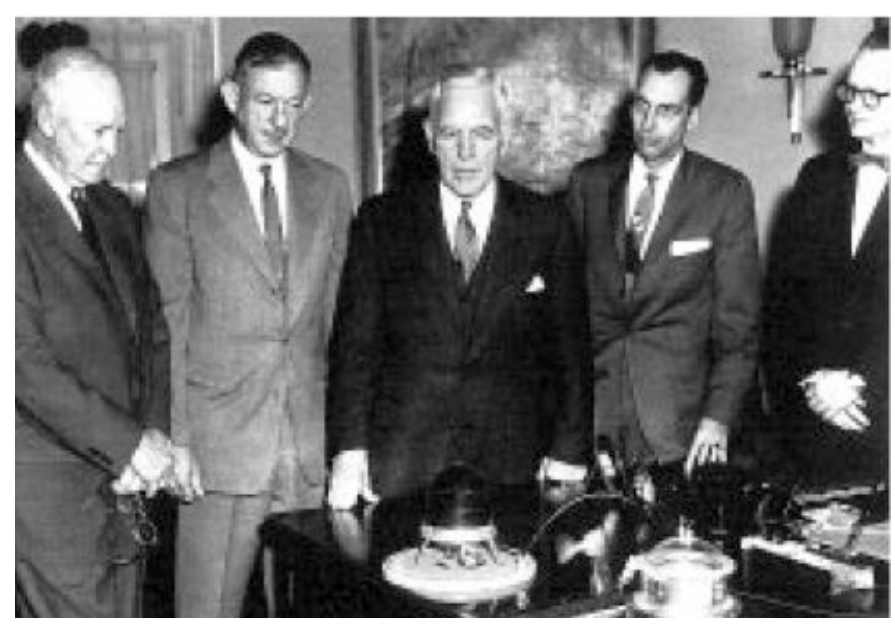

Oval Office Presentation of SNAP-3 in January 1959 


\section{Early Flight Units}

\section{SNAP-3B}

- Supplemental power source for Transit 4A and 4B navigational satellites

- Launched in June and Nov 1961 to 1,100 km altitude

- RTG powered crystal oscillator and other sensitive electronic components

- Features:

- Pu-238 metal fuel and Pb-Te thermoelectrics

- $2.7 \mathrm{We}$ BOM, $2.1 \mathrm{~kg}, 1.3 \mathrm{We} / \mathrm{kg}$ specific power

- 5-year design lifetime: 4A and 4B RTGs operated for 9 and $>15$ years, respectively

\section{SNAP-9A}

- Primary power source on Transit 5BN-1 and 5BN-2 navigational satellites

- Launched in Sept and Dec 1963

- Features:

- SNAP-3B fuel form and thermoelectrics

- $25 \mathrm{We}$ BOM, $12.3 \mathrm{~kg}, 2.0 \mathrm{We} / \mathrm{kg}$ specific power

- 6-year design lifetime: 5BN-1 failed in 9 months due to electrical problems, 5BN-2 RTG operated $>6$ years

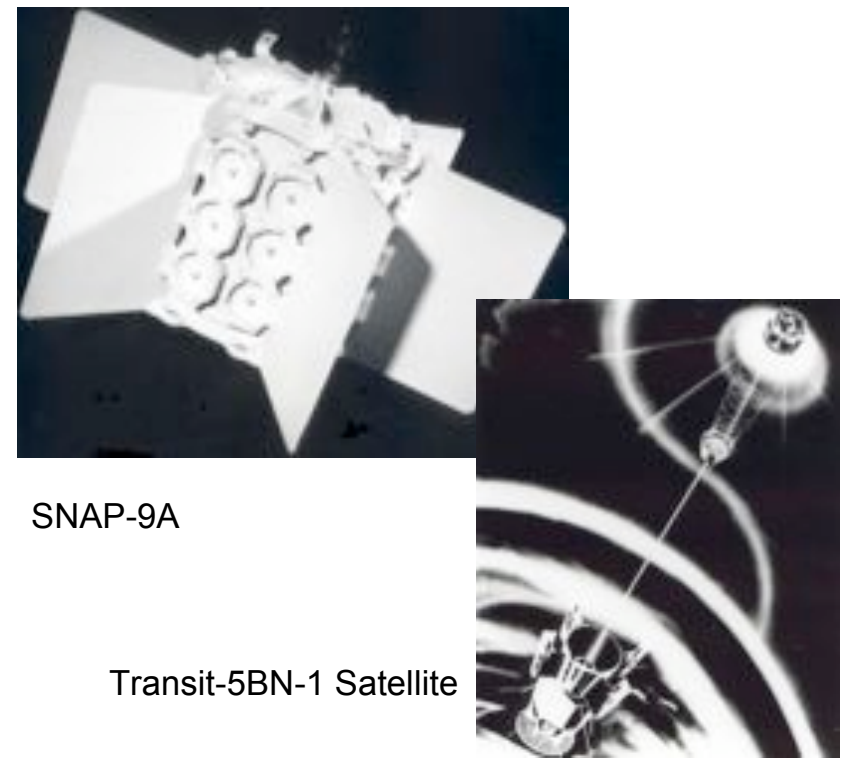




\section{SNAP-19B}

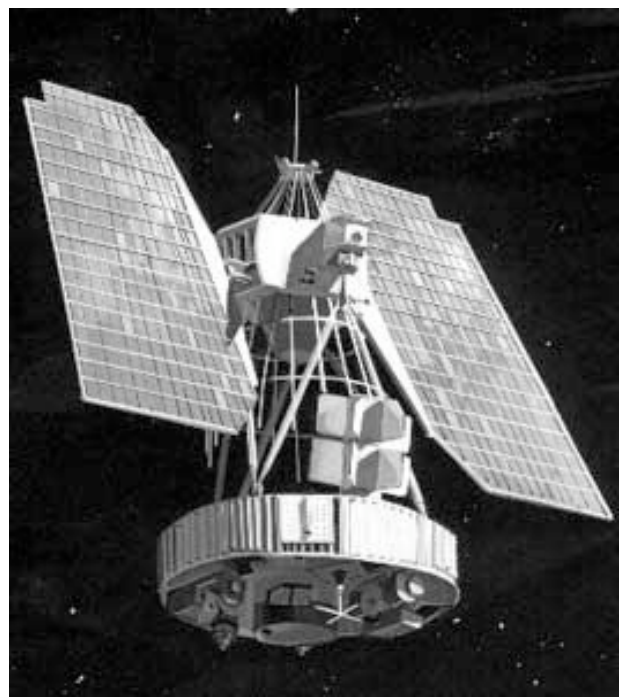

Nimbus III Satellite

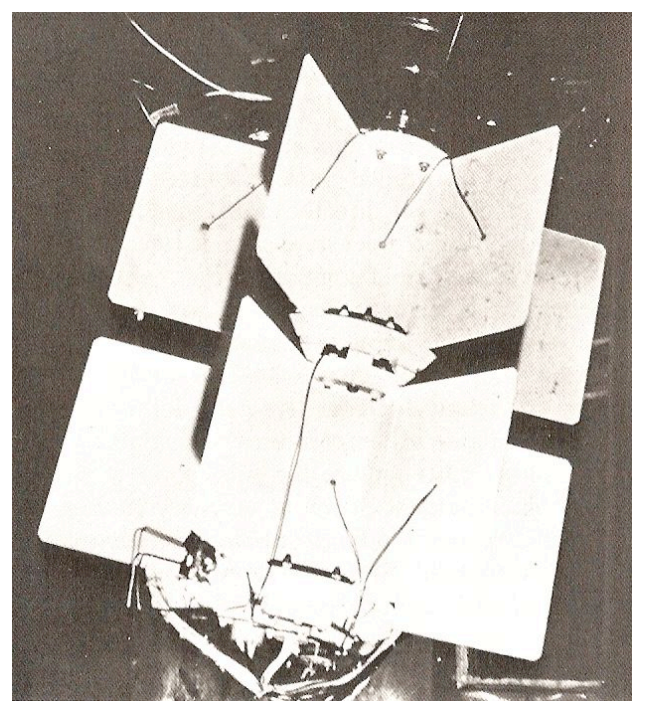

Assembly of 2 SNAP-19B RTGs

\section{Nimbus Meteorological Satellite}

- First NASA application of RPS

- 2 RTGs served as primary power source

- Nimbus B-1 launch on 18 May 1968

- Launch vehicle failure forced destruction by Range Safety Officer

- Agena Upper Stage in Santa Barbara Channel

- RTGs recovered and fuel reused

- Nimbus III (B-2) launch on 14 April 1969

- Operated find for 2.5 years

- Sharp degradation in performance due to sublimation of thermoelectric materials and loss of hot junction bond due to internal cover gas depletion

- Features:

- Intact Impact Heat Source (IIHS)

- PuO2 microspheres in capsules for fuel - microspheres too big for inhalation

- Pb-Te thermoelectrics (6.2\% efficiency)

- 23.5 We BOM, 13.4 kg, 2.1 We/kg specific power

- 2-year design lifetime 


\section{Early Flight Units}

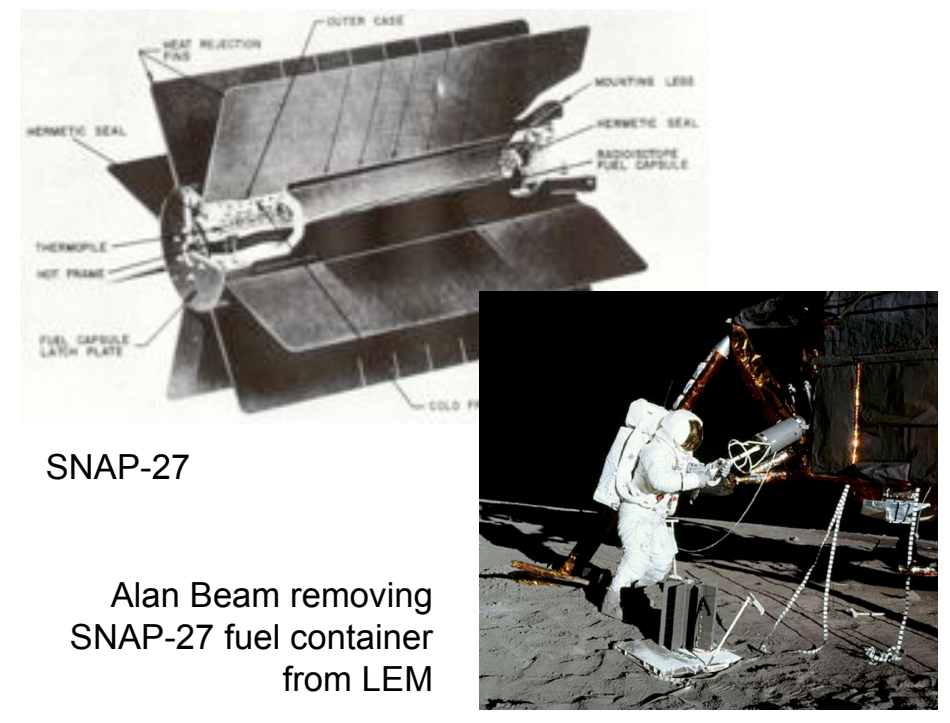

\section{SNAP-27}

- Power source for Apollo Lunar Surface Experiment Package (ALSEP)

- Deployed on Apollo missions 12, 14, 15, 16 and 17

- Features:

- 238PuO2 fuel metal fuel and Pb-Te thermoelectrics

- 63.5 We BOM, $19.6 \mathrm{~kg}, 3.2 \mathrm{We} / \mathrm{kg}$ specific power

- 2-year design lifetime: All deployed units operated 5-8 years until ALSEP station shutdown

\section{Transit RTG}

- Used on Transit Triad satellite

- Launched in Sept 1972

- Served as primary source with PV/battery auxiliary power

- Features:

- 238PuO2/Mo Cermet fuel

- Radiatively-coupled Pb-Te thermoelectrics

- 35.6 We BOM, $13.6 \mathrm{~kg}, 2.6 \mathrm{We} / \mathrm{kg}$ specific power

- 5-year design lifetime: RTG still operating as of Feb 2008

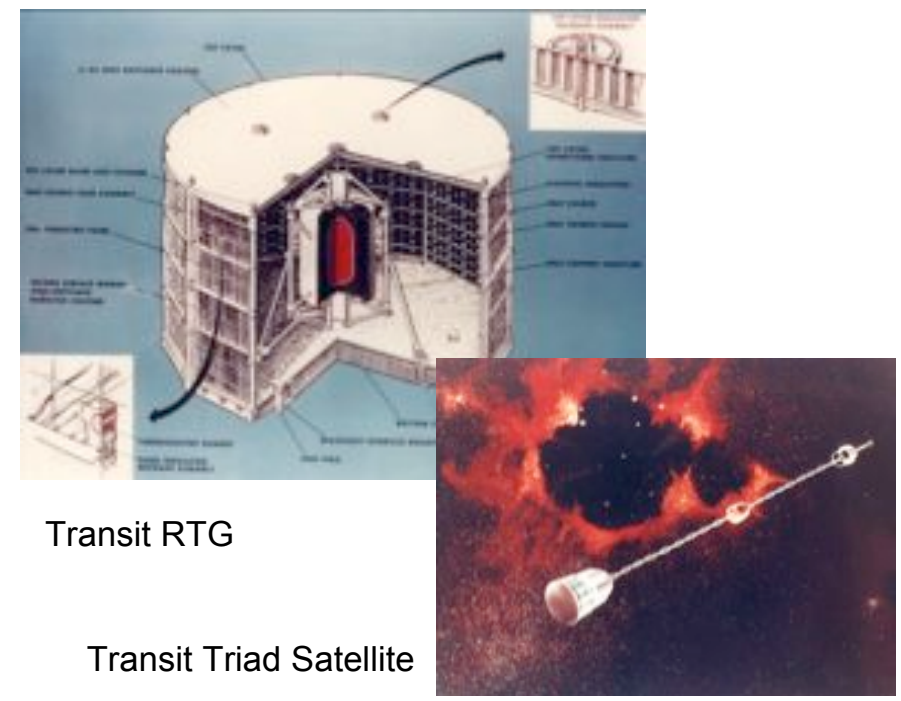




\section{SNAP-19}

\section{Pioneer Deep Space Probes}

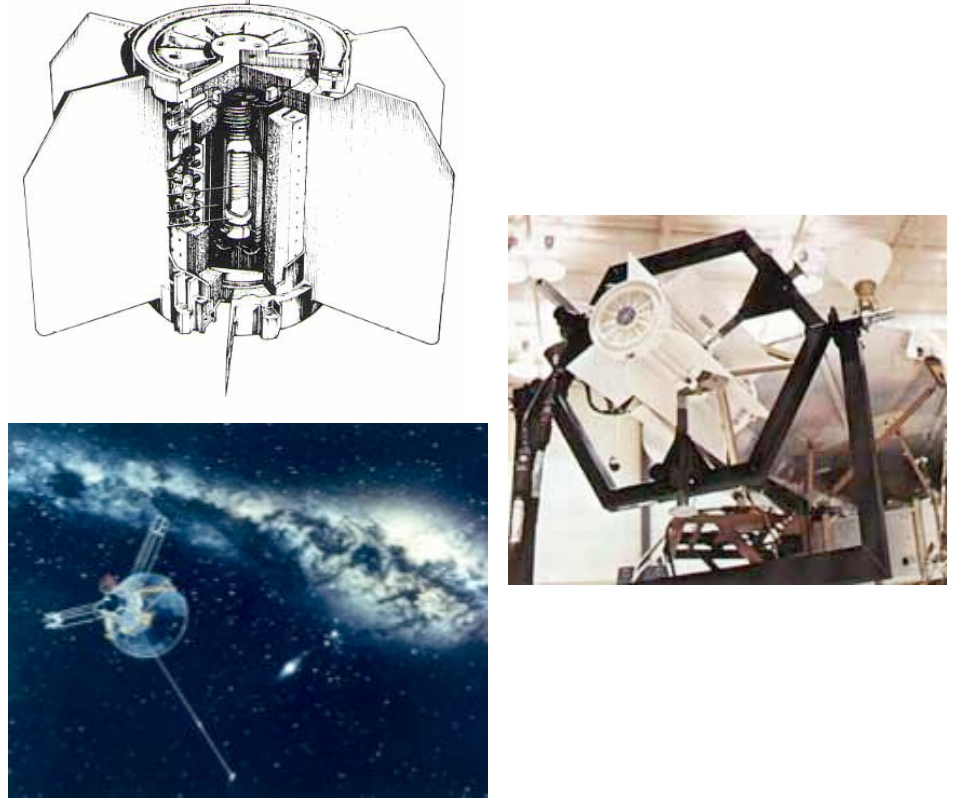

- Pioneer 10 and 11 each had 4 SNAP-19 RTGs for primary power source

- Modified version of SNAP-19B

- Incorporation of TAGS/Sn-Te material for thermoelectrics - increased efficiency $(6.2 \%)$ and lifetime

- Longer, narrower generator size

- 40.3 We BOM, $13.6 \mathrm{~kg}, 3.0 \mathrm{We} / \mathrm{kg}$ specific power

- 5-year design lifetime

- Launch on 2 March 1972 and 6 April 1973

- Last signal from Pioneer 10 in 2003

- Last signal from Pioneer 11 in 1995

\section{Viking Landers}

- Vikings 1 and 2 each had 2 RTGs for primary power

- Modified for Mars environment

- Larger and more massive than Pioneer

- 42.6 We BOM, $15.2 \mathrm{~kg}, 2.8 \mathrm{We} / \mathrm{kg}$ specific power

- 90-day operational requirement

- Launch on 20 Aug 1975 and 9 Sept 1975

- Last data from Viking 1 in 1982

- Relay link from Viking 2 lost in 1979

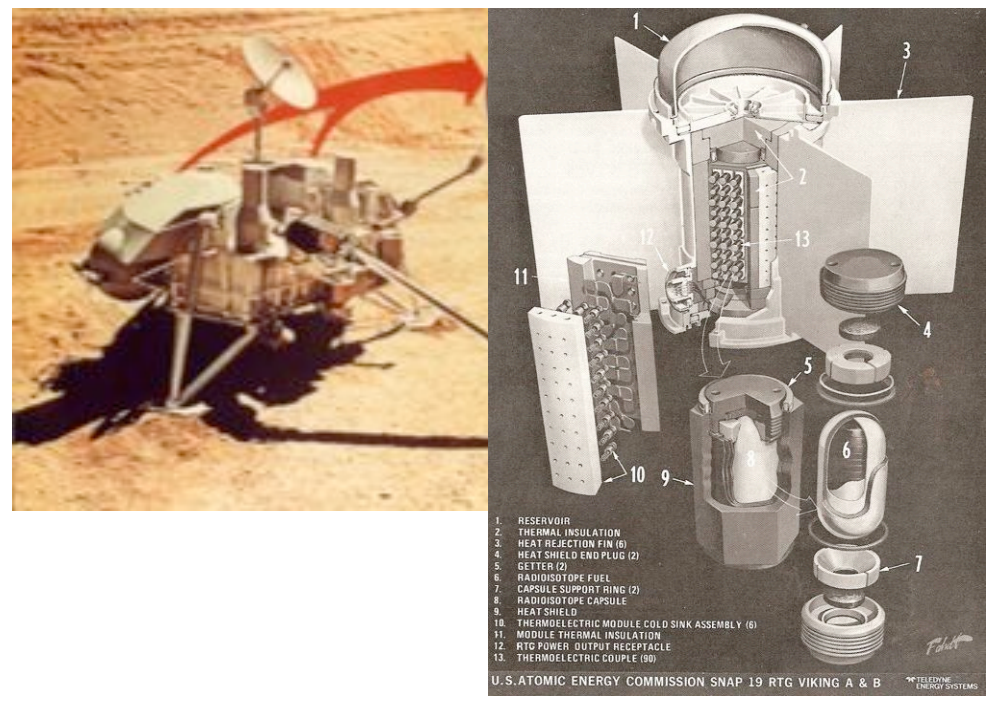




\section{High-Performance RTGs}

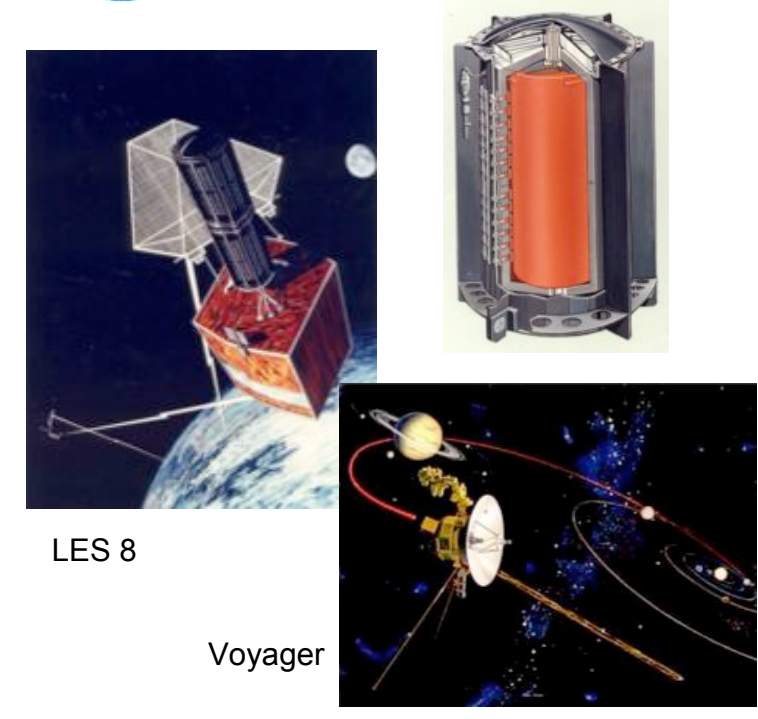

\section{General Purpose Heat Source (GPHS) RTG}

- Primary Power on 4 Most Recent Deep Space Spacecraft

- Galileo (May 1989)

- Ulysses (1990)

- Cassini (1997)

- Pluto New Horizons (2006)

- Features:

- 238PuO2 Fuel and Si-Ge Thermoelectrics (6.8\% efficiency)

- $56.1 \mathrm{~kg}, 292 \mathrm{We}$ BOM, 5.2 We/kg specific power

- All RTGs, except Galileo's, operating as of Feb 2008

\section{Multi-Hundred Watt (MHW) RTG}

- Primary Power on 4 Spacecraft

- Lincoln Experimental Satellites (LES) 8 and 9 (Launched in 1976)

- Voyager 1 and 2 Space Probes (Launched in 1975)

- Features:

- 238PuO2 Fuel and Si-Ge Thermoelectrics (6.6\% efficiency)

- $37.6 \mathrm{~kg}, 158 \mathrm{We}$ BOM, $4.2 \mathrm{We} / \mathrm{kg}$ specific power

- RTGs still operating as of Feb 2008

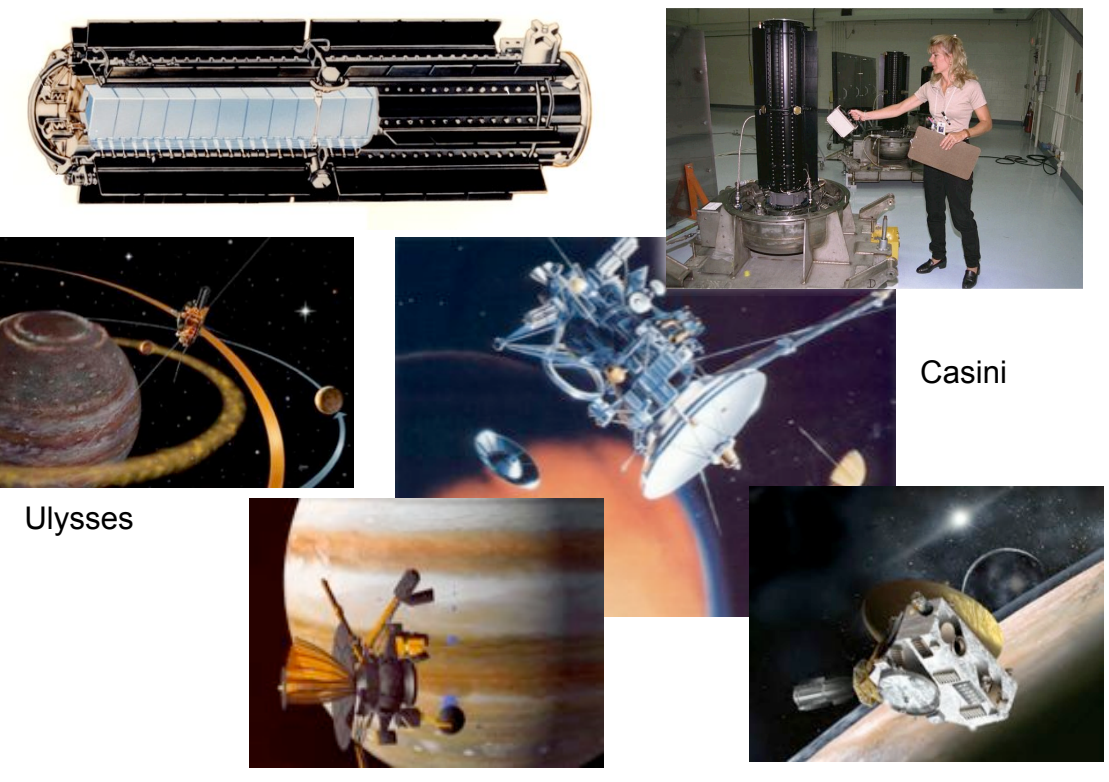

Galileo 


\section{Multi-Mission RTG (MMRTG)}

- Development funded by Mars Program for use on Mars Science Laboratory - launch in 2009

- 1 MMRTG serves as primary power source on large Mars surface rover

- Available for use on other surface and deep space missions

- Design Features:

-123We @ BOM; 99 We @ 14 yrs

- 8 GPHS heat sources per MMRTG

- $\mathrm{Pb}-\mathrm{Te} / \mathrm{TAGS}$ thermoelectrics (6.3\% efficiency)

- 44 kg, $2.8 \mathrm{We} / \mathrm{kg}$ specific power

- 14-year design lifetime

- Approx Dimensions: $66 \mathrm{~cm}$ (length) x $60 \mathrm{~cm}$ (dia)

- Milestones:

- Authority to Proceed - July 2003

- Completed Qualification Unit tests in 2007

- Flight unit being assembled and readied for shipment to the Cape
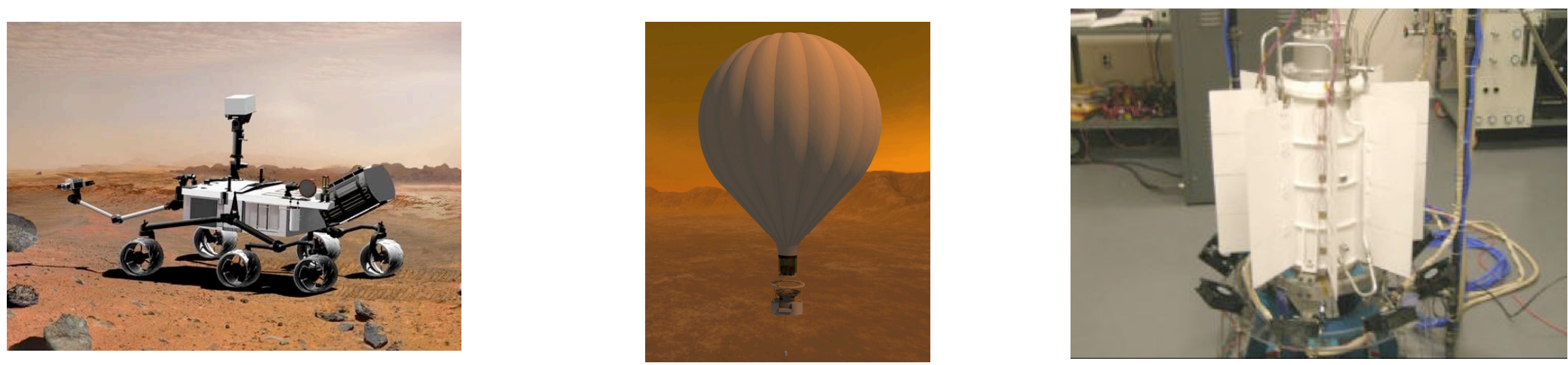


\section{Advanced Stirling Radioisotope Generator (ASRG)}

- Dramatic advancement in RPS capability

- High efficiency Stirling power conversion ( $\geq 30 \%$ )

- Substantial increase in specific power (2-3 times greater than MMRTG)

- Technology demonstration of flight-design generator with Stirling power conversion

- Qual-level thermal and vibrational tests

- Flight unit design processes

- Would be compatible for use on planetary surface and deep space missions - 14-year design lifetime

- Engineering Unit Features:

- $140 \mathrm{We}$

- 2 simulated GPHS heat sources per ASRG

- $20 \mathrm{~kg}, 7.0 \mathrm{We} / \mathrm{kg}$ specific power

- Flight Unit Features:

- $\geq 160 \mathrm{We}$

- 2 GPHS heat sources per MMRTG

- $\leq 20 \mathrm{~kg}, 8.0 \mathrm{We} / \mathrm{kg}$ specific power

- Potential Missions:

- Discovery/Scout - 2012/13 timeframe

- Titan or Europa Flagship - $\geq 2016$

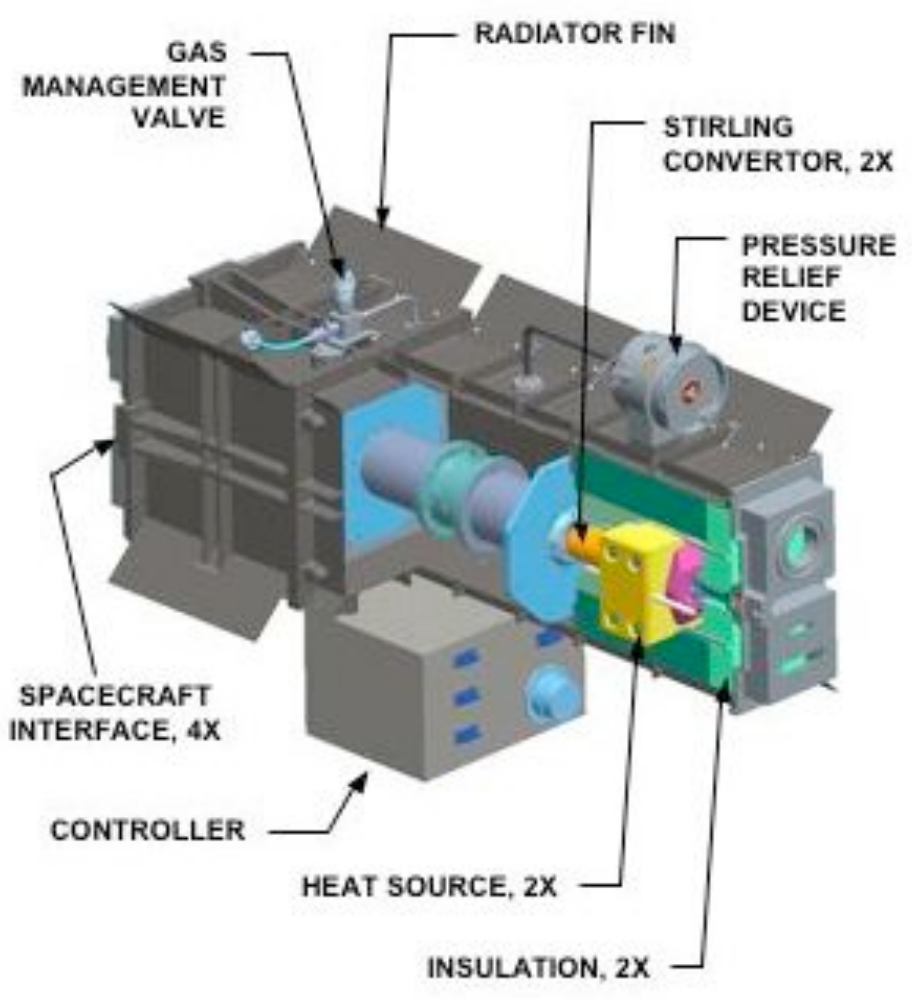

Sunpower-built Stirling Converter

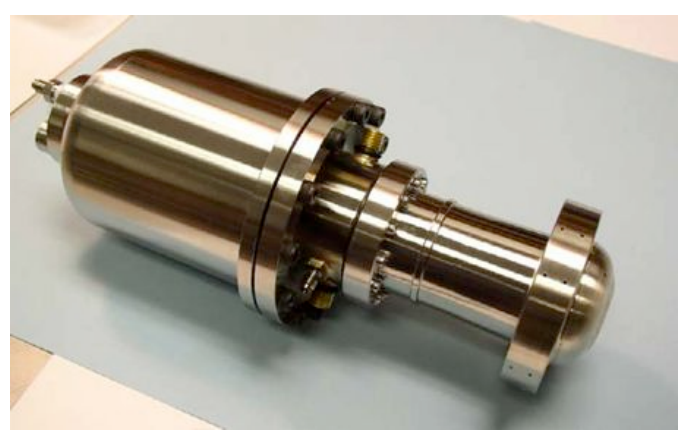

Sunpower-built Stirling Converter 


\section{ASRG is large improvement in RPS capability}

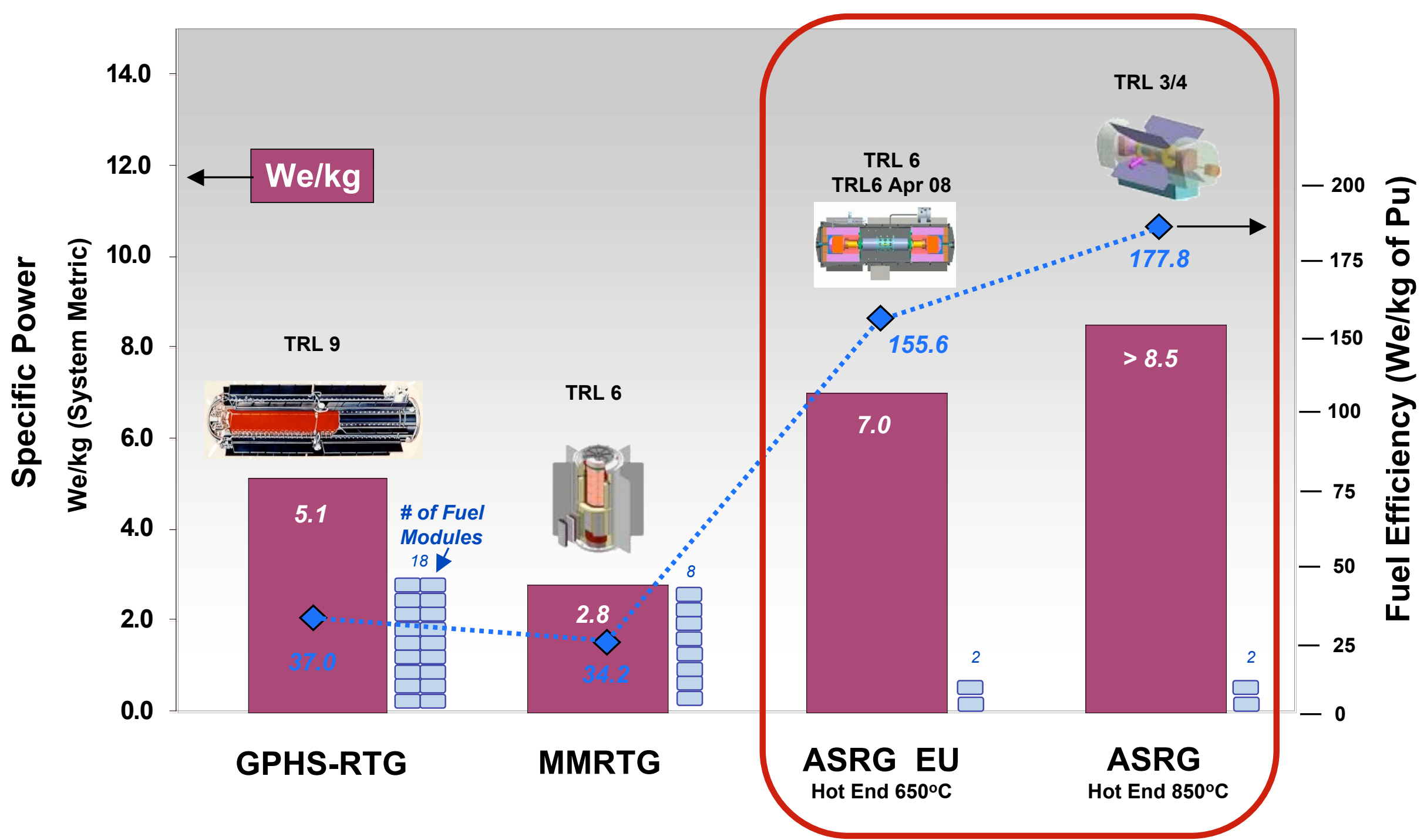

ASRG Provides High Specific Power RPS Generator 


\section{ASRG Technology Project Strategy}

- ASC Convertor Life and Reliability - Test, Test, Test

- Early hermetic developmental convertors for GRC extended operation

- Three pairs of ASCs now testing 24/7, > 26,000 hrs as of $2 / 08$

- ASRG Generator Life and Reliability

- ASRG EU reassembly @ GRC for life testing Aug/Sept 08

- Performance testing 24/7 operations

- Component and materials Life and Reliability - Testing \& Analysis

- Plan for 10 Pre-EU convertors to validate processes and product quality, and build ASC data base for ASRGs

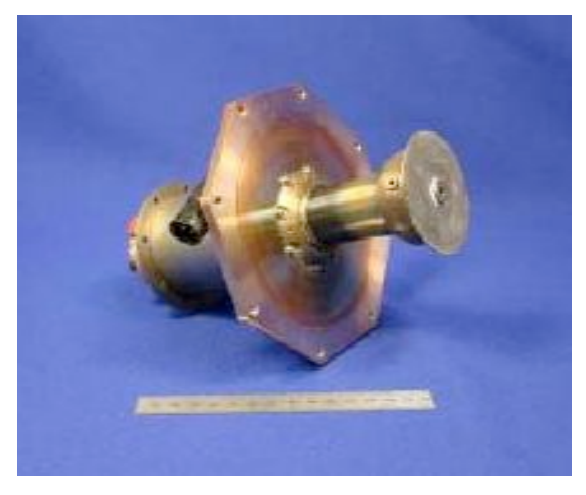

ASC-E Convertor

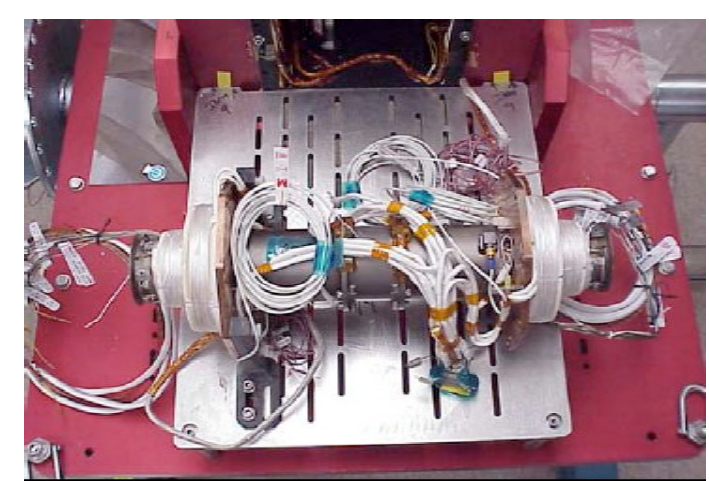

Pair of ASC-E Convertors during Integration

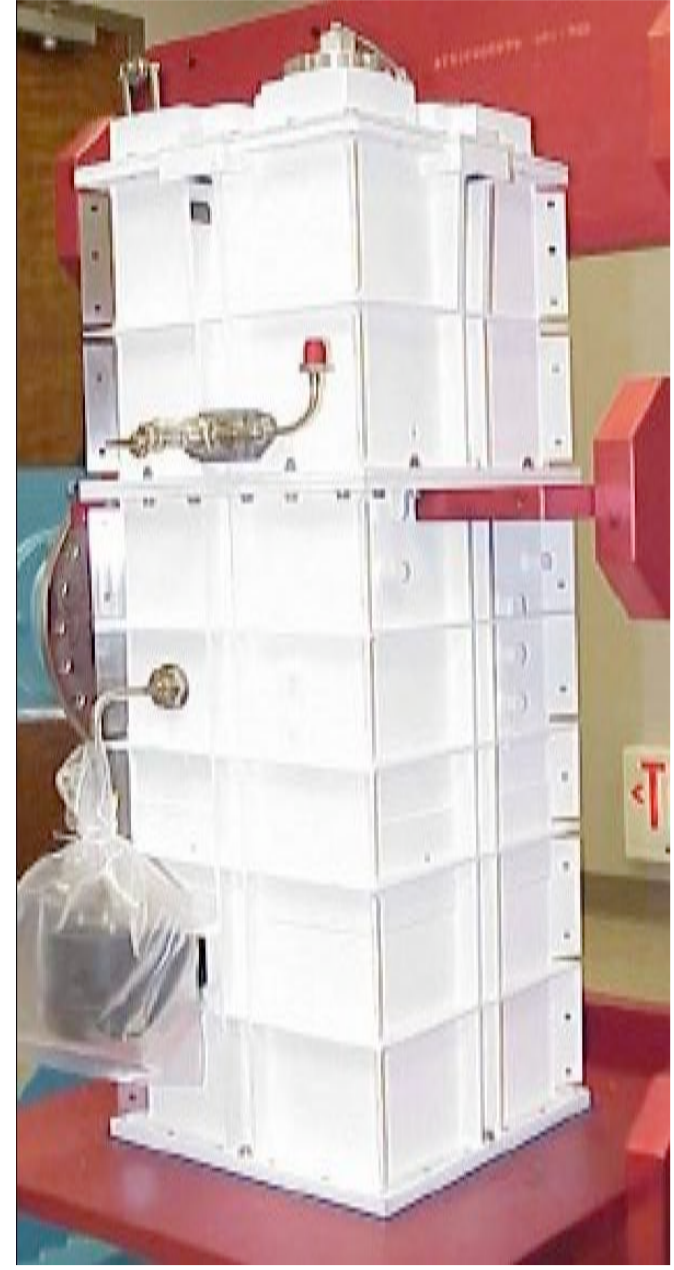

Completed ASRG Engineering Unit 


\section{Additional Applications for Small and Large RPS}

\section{Small RPS (mWe to several We)}

- Numerous potential planetary surface and space applications (e.g., networked science stations, deployable mini-payloads)

- 3 general size ranges using existing Pu-238 thermal sources

- 40-80 mW (based on 1-few RHUs)

- 0.1-few W (based on multiple RHUs or fractional GPHS)

- 10-20 W (based on single GPHS module)

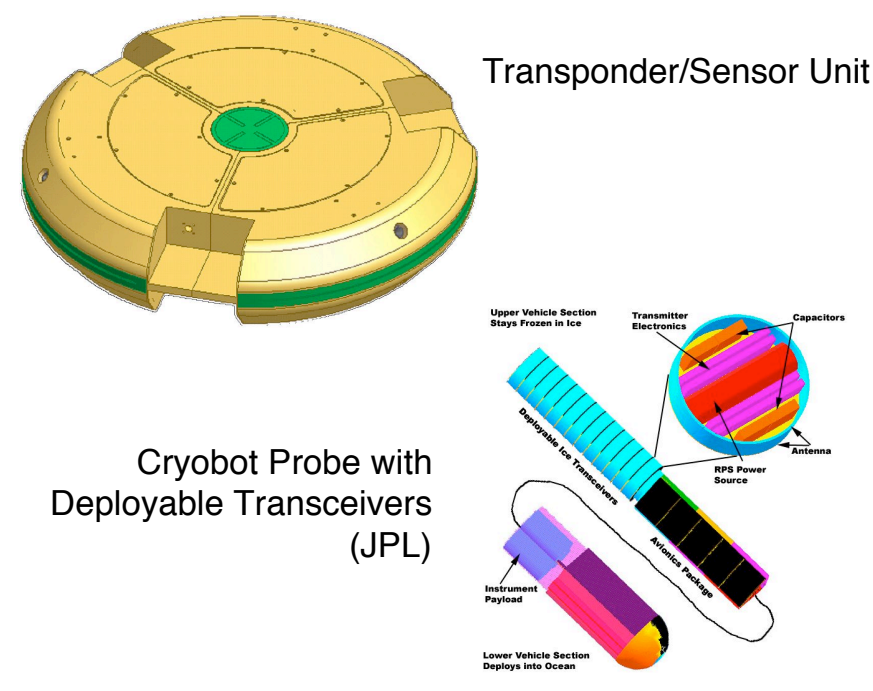

\section{Radioisotope Electric Propulsion (REP)}

- Low-power NEP based on RPS as principal power source

- Enables use of high-performance electric propulsion independent of distance from Sun (i.e., deep space)

- Science application for large power reqmts ( $\geq 1 \mathrm{kWe})$

- Compatibility on small spacecraft permits launch system injection into $\mathrm{C} 3>0$ and offsets performance disadvantage of low specific power

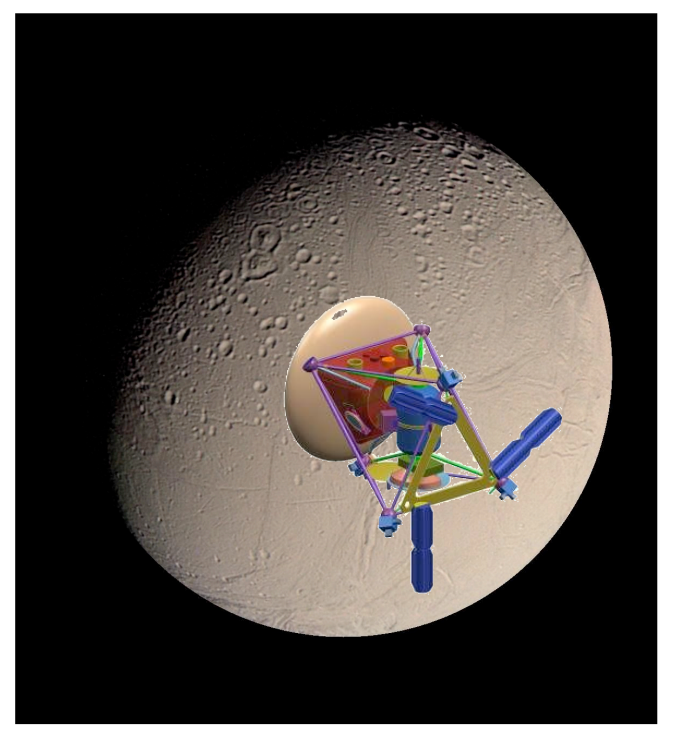




\section{Summary}

- RPS is one of the great success stories of the Space Age.

- Enabled some of the most exciting and ambitious space missions over the last 40 years

- Even with no new technologies, RPS will continue to be a mainstay for deep space exploration.

- New Stirling technology promises to greatly expand mission capabilities in future.
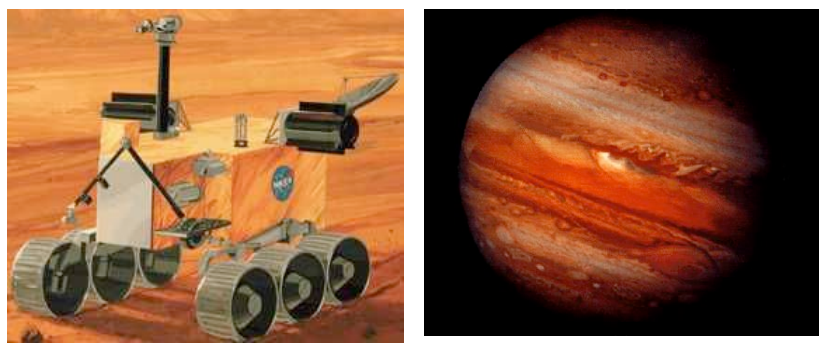

- Improved spacecraft mass performance

- Better Pu-238 utilization

- REP missions

- Main challenge for RPS is the limited availability of Pu-238 fuel. Even with exclusive use of ASRG after MSL, only $<4 \mathrm{~kW}$ available for future missions.

- Resume national Pu-238 production?

- Alternative production techniques?

- Alternative isotopes?
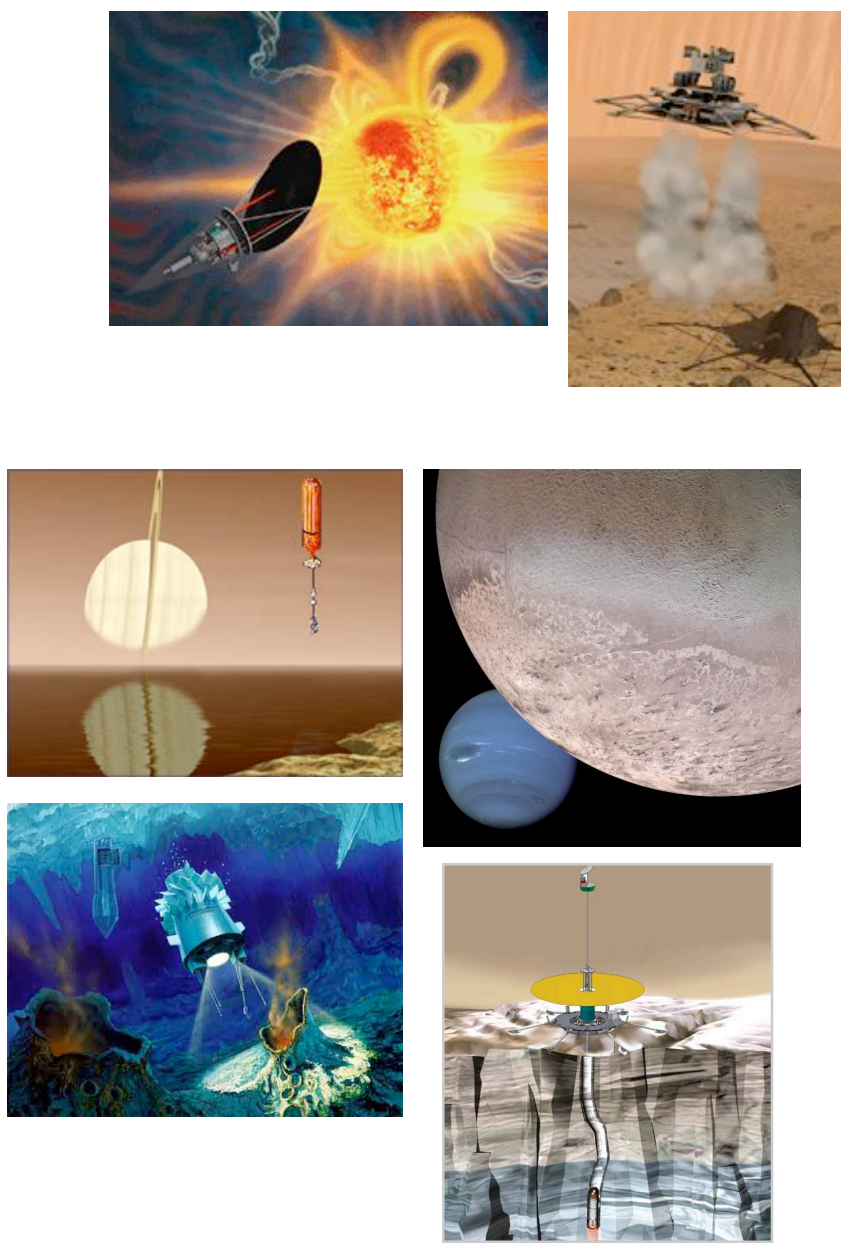